Keywords: tritium, radiation damage, EPDM elastomer

Retention: Permanent

\title{
Effects of Gamma Irradiation on EPDM Elastomers
}

Dr. Elliot A. Clark

Savannah River National Laboratory

September 2011

Savannah River National Laboratory

Savannah River Nuclear Solutions, LLC Aiken, SC 29808

Prepared for the U.S. Department of Energy under

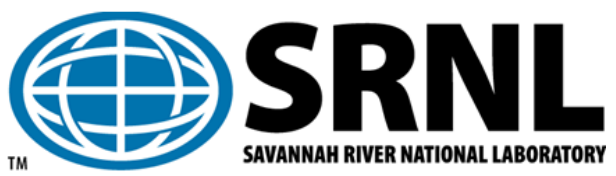
contract number DE-AC09-08SR22470. 


\section{DISCLAIMER}

This work was prepared under an agreement with and funded by the U.S. Government. Neither the U.S. Government or its employees, nor any of its contractors, subcontractors or their employees, makes any express or implied:

1. warranty or assumes any legal liability for the accuracy, completeness, or for the use or results of such use of any information, product, or process disclosed; or

2. representation that such use or results of such use would not infringe privately owned rights; or

3. endorsement or recommendation of any specifically identified commercial product, process, or service.

Any views and opinions of authors expressed in this work do not necessarily state or reflect those of the United States Government, or its contractors, or subcontractors.

\section{Printed in the United States of America \\ Prepared for U.S. Department of Energy}




\section{EXECUTIVE SUMMARY}

Two formulations of EPDM elastomer, one substituting a UV stabilizer for the normal antioxidant in this polymer, and the other the normal formulation, were synthesized and samples of each were exposed to gamma irradiation in initially pure deuterium gas to compare their radiation stability. Stainless steel containers having rupture disks were designed for this task. After 130 MRad dose of cobalt-60 radiation in the SRNL Gamma Irradiation Facility, a significant amount of gas was created by radiolysis; however the composition indicated by mass spectroscopy indicated an unexpected increase in the total amount deuterium in both formulations. The irradiated samples retained their ductility in a bend test. No change of sample weight, dimensions, or density was observed. No change of the glass transition temperature as measured by dynamic mechanical analysis was observed, and most of the other dynamic mechanical properties remained unchanged. There appeared to be an increase in the storage modulus of the irradiated samples containing the UV stabilizer above the glass transition, which may indicate hardening of the material by radiation damage. 


\section{CONTENTS}

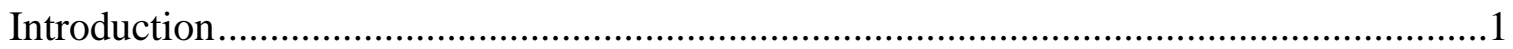

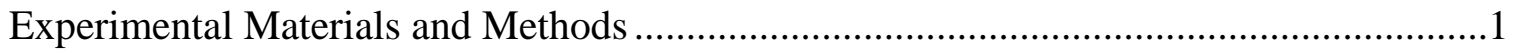

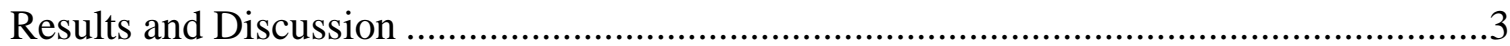

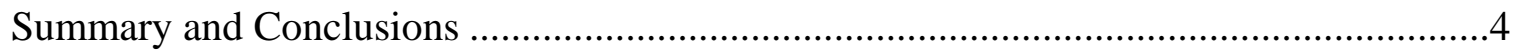

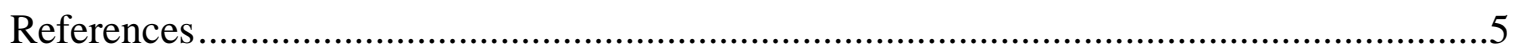

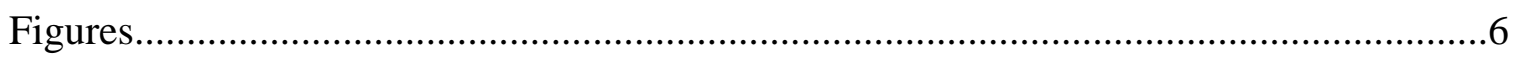

\section{FIGURES}

1. Photograph of sample exposure container ................................................... 6

2. Photograph of bend tester ....................................................................... 7

3. Graphs of mole gas in containers of SRNL-1 and SRNL-KCP samples..............8

4. Storage modulus versus temperature for one sample, illustrating the tangent intersection method of ASTM E 1640 .......................................................... 9

5. Storage modulus, loss modulus, and tan delta of unexposed SRNL-KCP ......... 10

6. Average storage modulus for the two formulations and exposed/unexposed

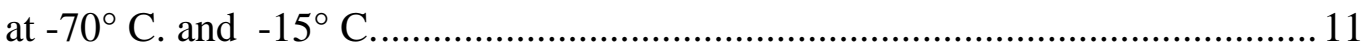

\section{ABBREVIATIONS}

SRNL Savannah River National Laboratory

SRS Savannah River Site

EPDM Ethylene propylene diene monomer

DMA Dynamic Mechanical Analysis (Analyzer) 


\section{$\underline{\text { Introduction }}$}

Polymeric materials become damaged by exposure over time to ionizing radiation. Despite the limited lifetime, polymers have unique engineering material properties and polymers continue to be used in tritium handling systems. In tritium handling systems, polymers are employed mainly in joining applications such as valve sealing surfaces (eg. Stem tips, valve packing, and O-rings).

Because of the continued need to employ polymers in tritium systems, over the past several years, programs at the Savannah River National Laboratory have been studying the effect of tritium on various polymers of interest [1-5]. In these studies, samples of materials of interest to the SRS Tritium Facilities (ultra-high molecular weight polyethylene (UHMW-PE), polytetrafluoroethylene (PTFE, Teflon ${ }^{\circledR}$ ), Vespel ${ }^{\circledR}$ polyimide, and the elastomer ethylene propylene diene monomer (EPDM)) have been exposed in closed containers to tritium gas initially at 1 atmosphere pressure. These studies have demonstrated the degradation of properties when exposed to tritium gas. Also, the radiolytic production of significant amounts of hydrogen has been observed for UHMW-PE [1, 3] and EPDM [2, 3].

The study documented in this report exposes two similar formulations of EPDM elastomer to gamma irradiation in a closed container backfilled with deuterium. Deuterium is chemically identical to protium and tritium, but allows the identification of protium that is radiolytically produced from the samples. The goal of this program is to compare and contrast the response of EPDM exposure to two different types of ionizing radiation in a similar chemical environment.

\section{Experimental Materials and Methods}

\section{Material Synthesis}

Two formulations of EPDM were compounded by the RD Rubber Technology Corporation (Table I), termed SRNL-KCP and SRNL-1 for this study.

\begin{tabular}{|l|l|}
\hline Component & Parts by Weight \\
\hline Royaline 580 HT & 100 \\
\hline Zic-Stick 85 & 5 \\
\hline N-990 Carbon Black & 40 \\
\hline N-539 Carbon Black & 25 \\
\hline Dicup 40C & 12 \\
\hline Flectol H Antioxidant & 2 \\
\hline SR350 (TMP TMA) & 10 \\
\hline
\end{tabular}

Table I. Components and amount in parts by weight in SRNL-KCP. SRNL-1 is identical except Flectol H Antioxidant is replaced by Cyasorb UV5411 UV Stabilizer, same part by weight.

The two formulations were identical except SRNL-KCP had an antioxidant (Table I), and SRNL-1 replaced this component with a UV stabilizer. Each formulation was combined using a two roll mill, press cured using a moving die rheometer at $166{ }^{\circ} \mathrm{C}$, followed by a post cure at $182{ }^{\circ} \mathrm{C}$ in a vacuum oven for 2- 
4 hours. Sheets 5 3/4 " by 5 3/4" by $1 / 16$ ” were produced. Samples for exposure and testing were cut from these sheets.

\section{Exposure Containers}

Stainless steel containers were designed having a rupture disk to contain the samples and deuterium gas during exposure (Fig.1). Fabricated from a standard 2 3/4" CF type vacuum connection and a Nupro $\mathrm{H}$ series valve, the rupture disk burst pressure is 100 psig. This burst pressure was based on stress analysis and testing of the container using ASME pressure vessel design code. The design pressure is full vacuum to 100 psig and the design temperature is $100{ }^{\circ} \mathrm{F}$. Samples are inserted and removed from the container by opening the main flange connection.

\section{Sample preparation and preliminary measurements}

Twelve samples, six of each formulation, were cut in rectangular shape (nominally $1 \frac{1 / 4}{4}$ by 3/8”), and their actual dimensions (length, width, thickness) measured with calipers. The samples were weighed using a laboratory electronic balance. The six samples of each formulation were inserted into one of two containers. The two containers were closed, tightened, evacuated, and then backfilled with pure deuterium to 814 torr. Before loading with deuterium, the free volume in each container was measured using the loading manifold. The free volumes were 59.3 cc for the container with SRNL-1 samples, and 56.1 cc for the container with SRNL-KCP samples.

The two containers with samples and deuterium gas were placed in the Model 109 Irradiator in the SRNL Cobalt-60 Irradiation Facility. They were irradiated at ambient temperature for 459.66 hours. The irradiator dose rate at the beginning of the irradiation was $2.828 \times 10^{5} \mathrm{Rad} /$ hour, so the total dose was about 130 MRad (not corrected for attenuation by the container).

After irradiation, the containers were attached separately to a gas manifold. The manifold had been volume calibrated, and the gas in the container was released into the evacuated manifold to allow the pressure to be measured by a pressure transducer. The final pressure in the containers at the end of irradiation was then calculated using the known system volumes of the manifold. In addition, "grab" samples of each containers gas was taken to a mass spectrometer to determine the isotopic composition of the gas after irradiation.

\section{Dynamic Mechanical Analysis}

Dynamic mechanical analysis measures the elastic and viscoelastic parameters related to small cyclic deformation of materials- storage modulus, loss modulus, and tan delta. The storage modulus is the constant relating the amount of elastic deformation to a given applied load. The loss modulus is a measure of the time-dependent deformation under a given load at the applied cycling frequency, and provides insight to the relative amount of molecular motion occurring at the specific applied cycling frequency. Tan delta is the ratio of the loss modulus to the storage modulus, and was the parameter used in old resonant-type DMA tests. Tan delta is also normally reported with storage and loss modulus as a way of comparing DMA data from resonant test with non-resonant tests.

A TA Instruments Model 2980 dynamic mechanical analyzer was used for this study. It is a forced oscillation, non-resonant, constant amplitude instrument. The single-cantilever-beam clamp, or sample holder, was used, being the clamp of choice for measuring the glass transition temperature of elastomers. The oscillation amplitude was chosen to be 40 microns for all samples. To determine the optimal amplitude for testing, a so-called "amplitude sweep" was performed in a previous study [2] of EPDM in which the amplitude was varied. The range of amplitudes that lead to equal DMA parameter (storage 
modulus, loss modulus, tan delta) measurements reveal the region of "linear viscoelasticty" for the material.

Each DMA test involved stabilizing the temperature at the chosen lowest temperature $\left(-70{ }^{\circ} \mathrm{C}\right.$ for most of the tests), remaining at this temperature for 10 minutes to further stabilize the temperature around the sample, and then increasing the sample temperature at $1{ }^{\circ} \mathrm{C}$ per minute until the chosen highest temperature $\left(-10^{\circ} \mathrm{C}\right.$ for most tests). The dynamic mechanical properties were continuously measured during the controlled temperature rise. The TA 2980 has both electrical resistance heating and cooling by evaporated cold nitrogen gas from a liquid nitrogen container called the Gas Cooling Accessory (GCA) which is a part of the DMA system. The control software enables optimized control of cooling and heating for a given temperature and heating rate. Data was taken using the DMA Multi-Frequency mode, at frequencies of 1,3 , and $10 \mathrm{~Hz}$. The DMA continuously acquired data at each of the set frequencies in sequence during the increasing temperature scans. The sampling rate was set at $3.0 \mathrm{sec} / \mathrm{point}$, which specifies the time over which data is acquired for each set frequency. The system was calibrated at least once a month during the testing program.

\section{$\underline{\text { Results and Discussion }}$}

Sample Size, Mass, Density

The sample volume and mass for each of the six samples of a given formulation was added to calculate the relative change of volume and mass, and the density. The relative mass loss was $0.1 \%$ and the volume gain was $1.6 \%$ for SRNL-1 and $0.9 \%$ for SRNL-KCP. These numbers are insignificant and probably reflect the uncertainty in the measurements. The density was found to be about $1.13 \mathrm{~g} / \mathrm{cc}$, and did not change significantly with irradiation.

\section{Bend Test}

A small bench top vise (Fig. 2) was altered to perform bend tests per ASTM E 290 - 97a "Standard Test Methods for Bend Testing of Materials for Ductility". The specific test performed was a Semi-Guided test for thin material, Arrangement B. Three of the six exposed samples for each formulation were tested. No breaks were observed, and all samples could be fully bent $\left(180^{\circ}\right)$ and immediately straighten when released. No loss of ductility occurred during the exposure.

\section{Gas Analysis}

The final pressure in the SRNL-1 container was found to be 1973 torr, and in the SRNL-KCP container was 1996 torr. From the original deuterium pressure of 814 torr, this is a factor of about 2.4 increase in gas pressure caused by the irradiation. From the free volume of the container, the number of moles of gas can be calculated using the Ideal Gas Law- 0.00629 moles for SRNL-1 and 0.00602 moles for SRNLKCP

A low $\mathrm{Z}$ mass spectrometer was used to determine the composition of the grab samples from each container. For SRNL-1, the gas was $16 \% \mathrm{H}_{2}$ and $84 \% \mathrm{D}_{2}$, and for SRNL-KCP the gas was $17 \% \mathrm{H}_{2}$ and $83 \% \mathrm{D}_{2}$. When these compositions are applied to the total moles of gas in the container, the amount of deuterium is seen to have increased (Fig. 3). This is a completely unexpected result- in previous studies of EPDM samples in tritium gas, the tritium in the gas was removed and absorbed in the samples. If all of the additional gas created was protium, as expected, the final mole fractions would have been $59 \% \mathrm{H}_{2}$ and $41 \% \mathrm{D}_{2}$. These results may have resulted from experimental error. 


\section{Dynamic Mechanical Analysis Results}

The glass transition temperature, $\mathrm{T}_{\mathrm{g}}$, was determined for each sample using ASTM E 1640 "Standard Test Method for Assignment of the Glass Transition Temperature by Dynamic Mechanical Analysis”. The intersection of two tangents of the storage modulus versus temperature curve- the tangent of data below $\mathrm{T}_{\mathrm{g}}$ and the tangent at the inflection point of the sigmoidally changing storage modulus with temperature in the middle of the glass transition. The temperature of the tangents intersection is regarded as being $\mathrm{T}_{\mathrm{g}}$ (Fig. 4). The standard requires an applied frequency of $1 \mathrm{~Hz}$ and a temperature increase rate of 1 ${ }^{\circ} \mathrm{C} /$ minute, which were used in this study. The glass transition temperature of all samples (both formulations and both unexposed and gamma irradiated samples) was $-53^{\circ} \mathrm{C}$., with a population standard deviation of $1.5^{\circ} \mathrm{C}$.

An example of a full DMA scan shows the huge effect the glass transition has on the elastic and viscoelastic properties of the EPDM thorough the glass transition (Fig. 5). The temperature of the peaks in the Loss Modulus and Tan Delta curves increases when the excitation frequency increases; this means the glass transition occurs at higher temperatures for higher frequencies. This is expected and often observed in polymers. When these plots for other samples are compared, no significant change in viscoelastic properties is observed for either formulation. A convenient way to compare the storage moduli of different samples is to pick two temperatures- one significantly below $\mathrm{T}_{\mathrm{g}},-70{ }^{\circ} \mathrm{C}$ in this case, and one significantly above $\mathrm{T}_{\mathrm{g}},-15^{\circ} \mathrm{C}$, and compare the storage moduli (Fig. 6). There was no significant change of the storage modulus below $\mathrm{T}_{\mathrm{g}}$ (Fig. 6 a.) the population standard deviation being $801 \mathrm{MPa}$. For the modulus at $-15{ }^{\circ} \mathrm{C}$, there appears to be a significant hardening of the storage modulus for the SRNL-1 gamma irradiated samples (Fig. 6 b.), the population standard deviation being $11 \mathrm{MPa}$. This could imply that SRNL-1 is less resistant to degradation by gamma irradiation than SRNL-KCP at temperatures above the glass transition, however more study is needed to confirm this hypothesis.

\section{$\underline{\text { Summary and Conclusions }}$}

Two formulations of EPDM elastomer, one containing a UV stabilizer and the other an antioxidant normal for this type of elastomer, were synthesized and samples of each were exposed to gamma irradiation in initially pure deuterium gas to compare their radiation stability. A significant amount of gas was created by radiolysis; however the composition indicated by mass spectroscopy indicated an unexpected increase in the total amount deuterium. The irradiated samples retained their ductility in a bend test. No change of sample weight, dimensions, or density was observed for the irradiation dose tested. No change of the glass transition temperature was observed, and most of the other dynamic mechanical properties remained unchanged. Their appeared to be an increase in the storage modulus of the SRNL-1 gamma irradiated samples above the glass transition, which may indicate hardening by radiation damage. 


\section{$\underline{\text { References }}$}

1. “Effects of Tritium on UHMW-PE, PTFE, AND Vespel® polyimide”, E.A. Clark, K.L. Shanahan, Fusion Science and Technology, 52 (4), pp. 1007-1011 (Nov 2007).

2. “Tritium Effects on Dynamic Mechanical Properties of EPDM Elastomer”, E.A. Clark, G.C. Staack, Fusion Science and Technology, 54 (2), pp. 576-579 (2008).

3. “Tritium Effects on Dynamic Mechanical Properties of Polymeric Materials”, E.A. Clark, in Effects of Hydrogen on Materials Proceedings of the 2008 International Hydrogen Conference, ed. Brian Somerday, Petros Sofronis, Russell Jones, ASM International, Materials Park OH USA, pp. 726-734 (2009).

4. "Radiation Stability of Nafion Membranes used for Isotope Separation by Proton Exchange Membrane Electrolysis”, Elise B. Fox, Scott D. Greenway, and Elliot A. Clark. Fusion Science and Technology, 57 (2), pp. 103-111 (Feb. 2010).

5. "Investigation on the effects of beta and gamma irradiation on conducting polymers for sensor applications”, Marie C. Kane, Robert J. Lascola, Elliot A. Clark. Radiation Physics and Chemistry, 79, pp. 1189-1195 (2010). 


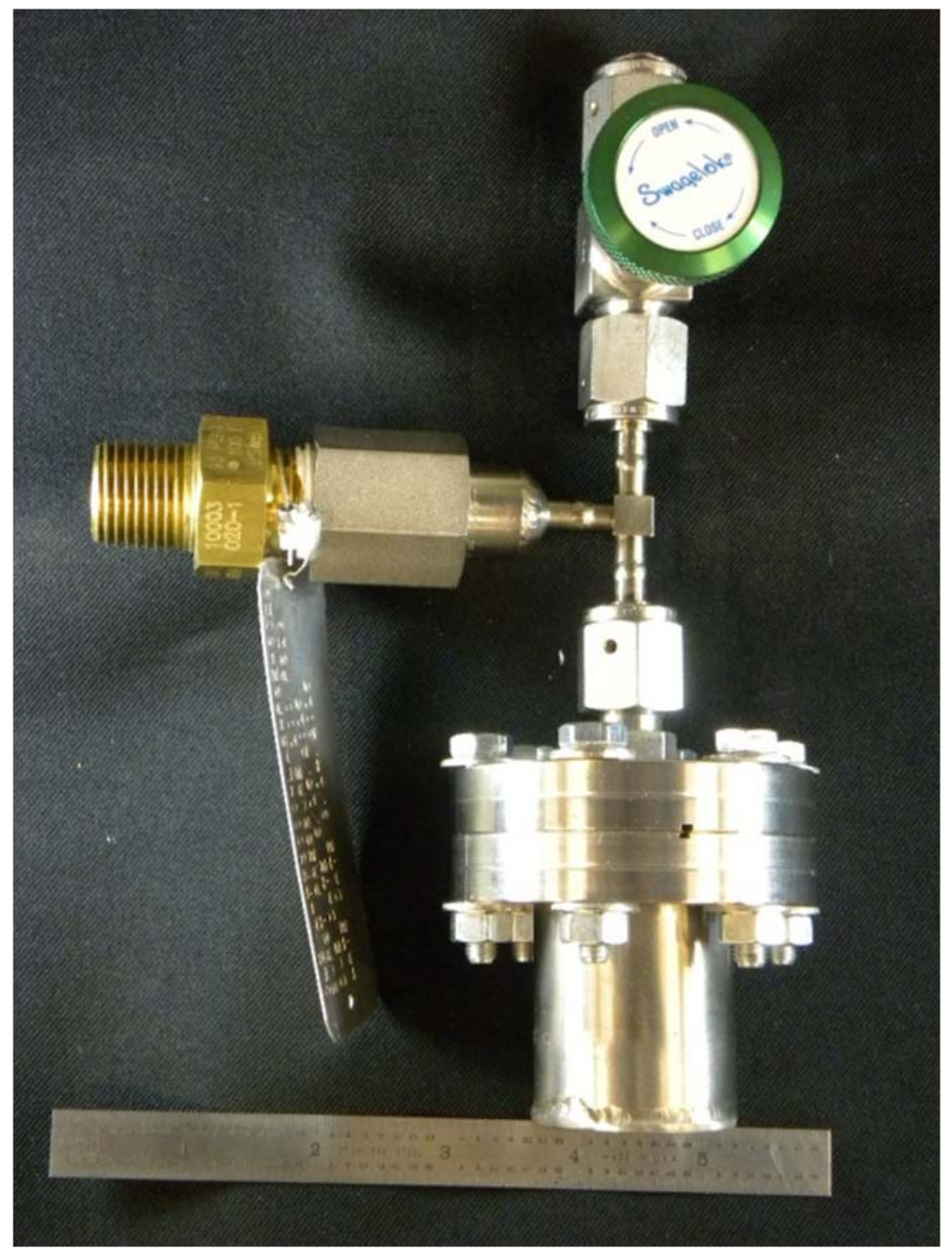

Figure 1. Photograph of sample exposure container, with valve and rupture disk. 


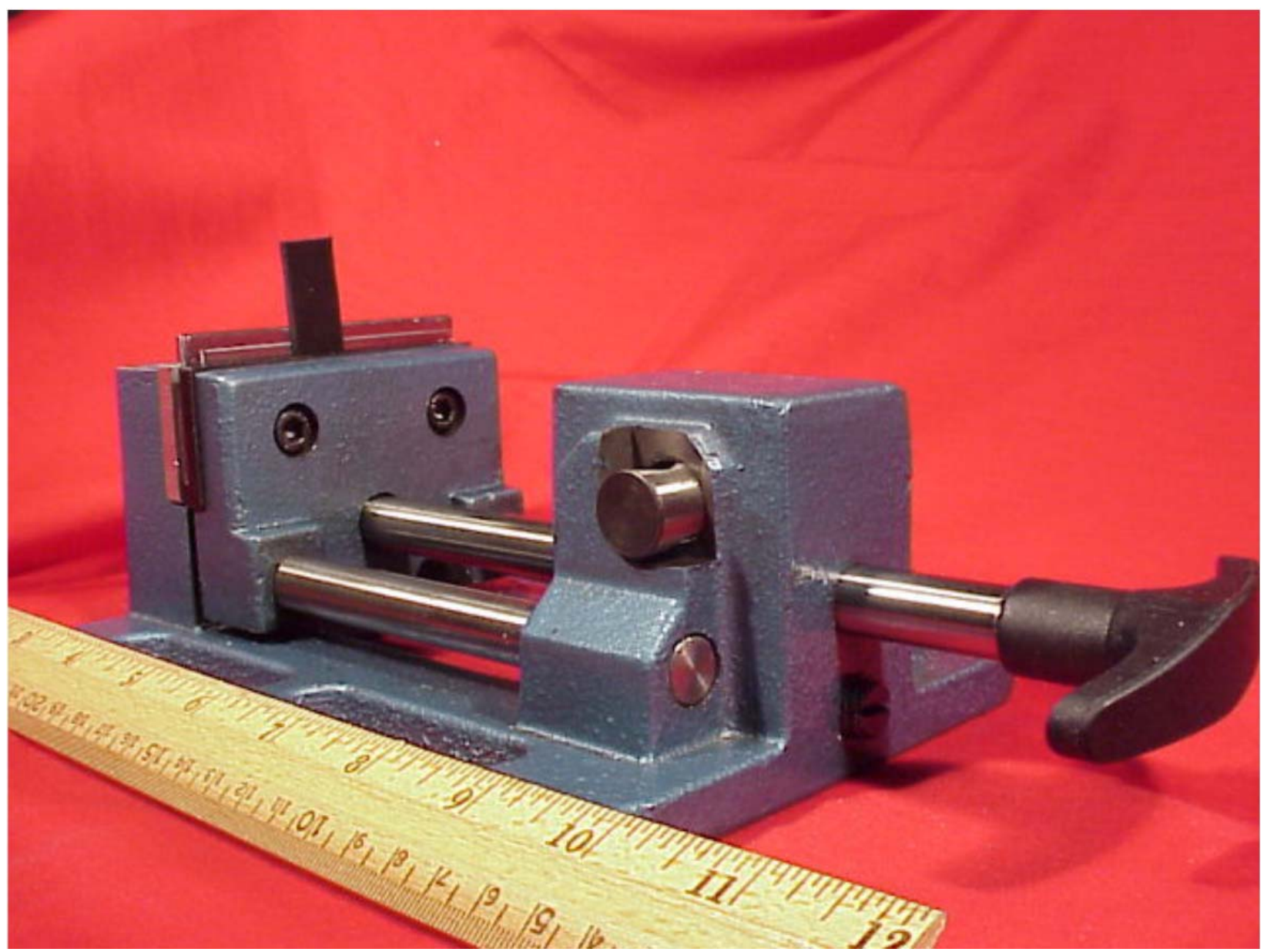

Figure 2. Photograph of small bench top vise altered for ASTM Bend Test. EPDM sample in vise is shown. 


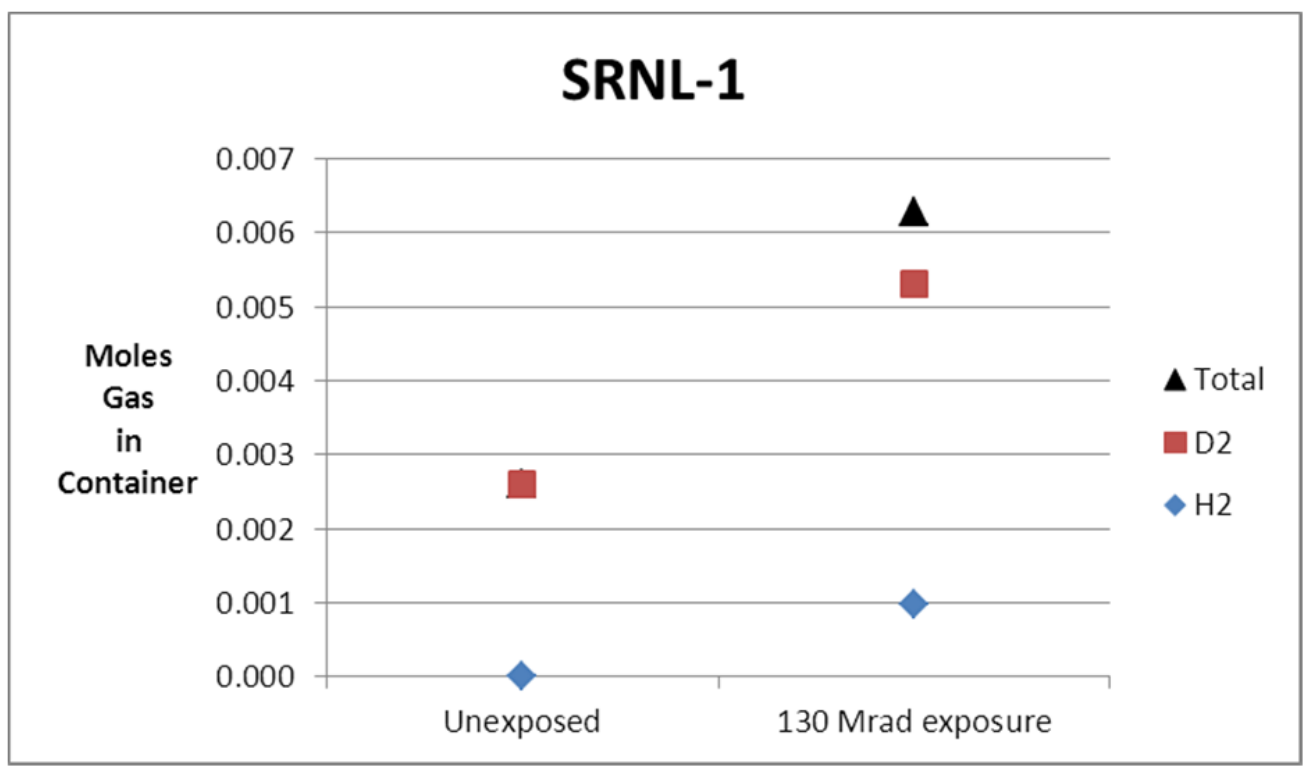

a.

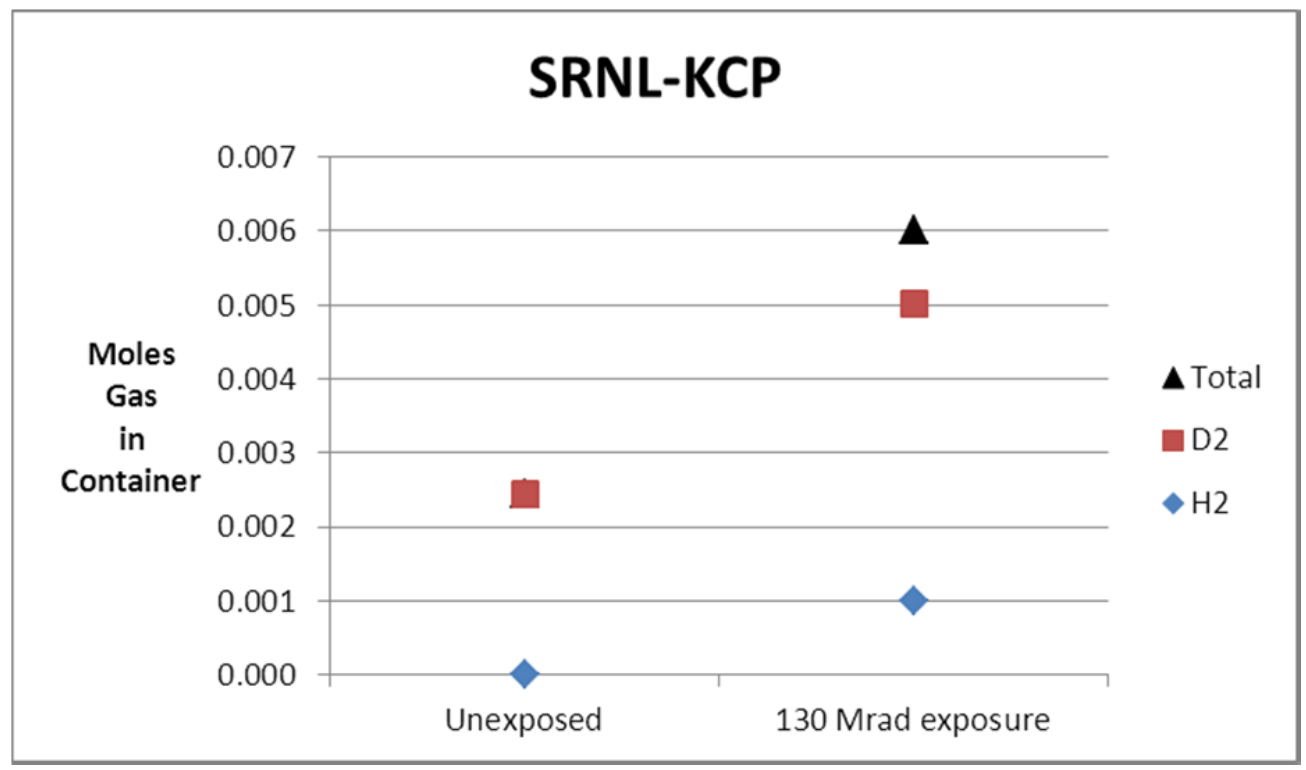

b.

Figure 3. Moles gas in container, protium deuterium, and total, for formulations a. SRNL-1 and b. SRNL-KCP. Note unusual increase in deuterium after irradiation. 


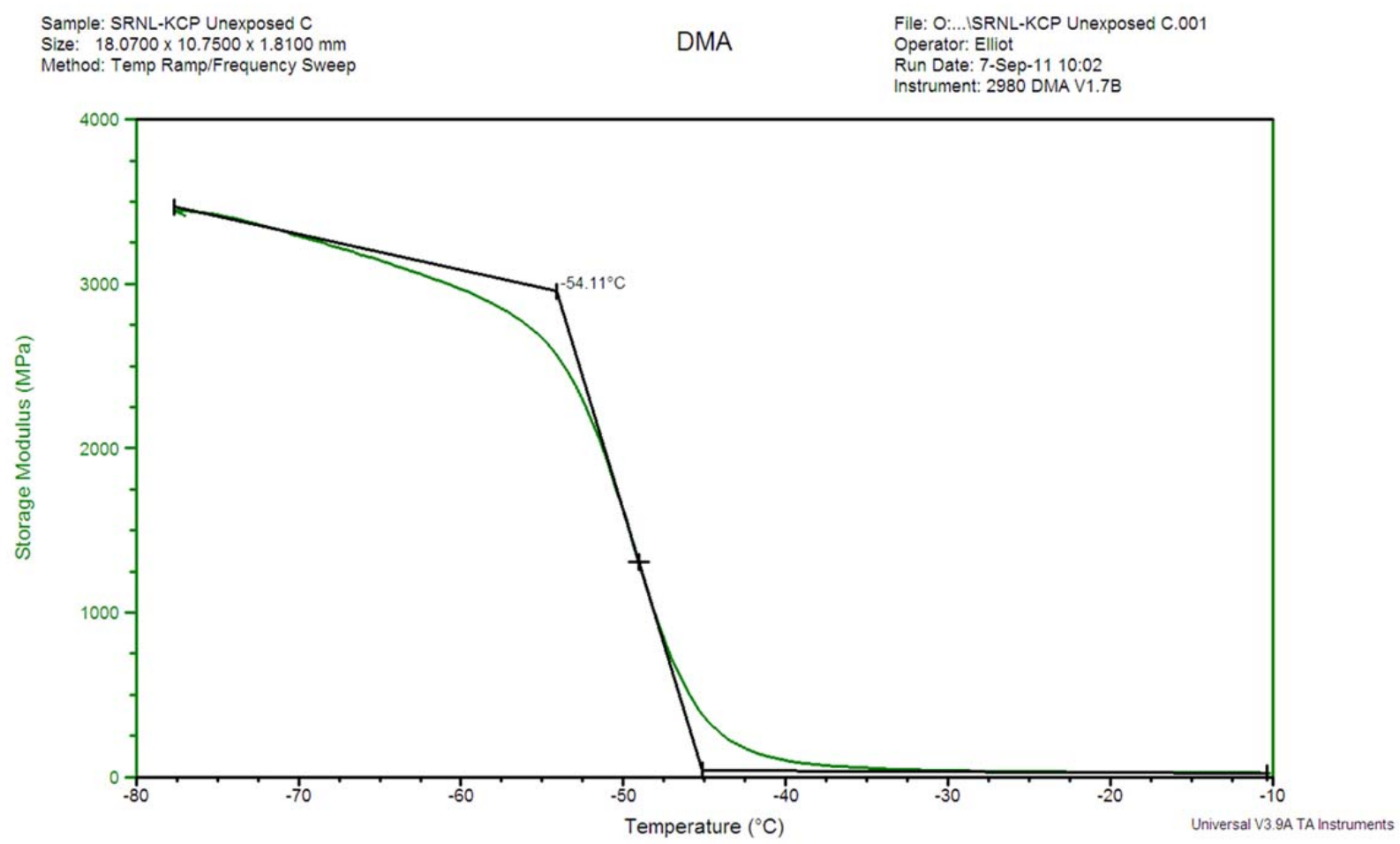

Figure 4. Storage modulus versus temperature for one sample tested, illustrating the tangent intersection method of ASTM E 1640 "Standard Test Method for Assignment of the Glass Transition Temperature by Dynamic Mechanical Analysis”. 


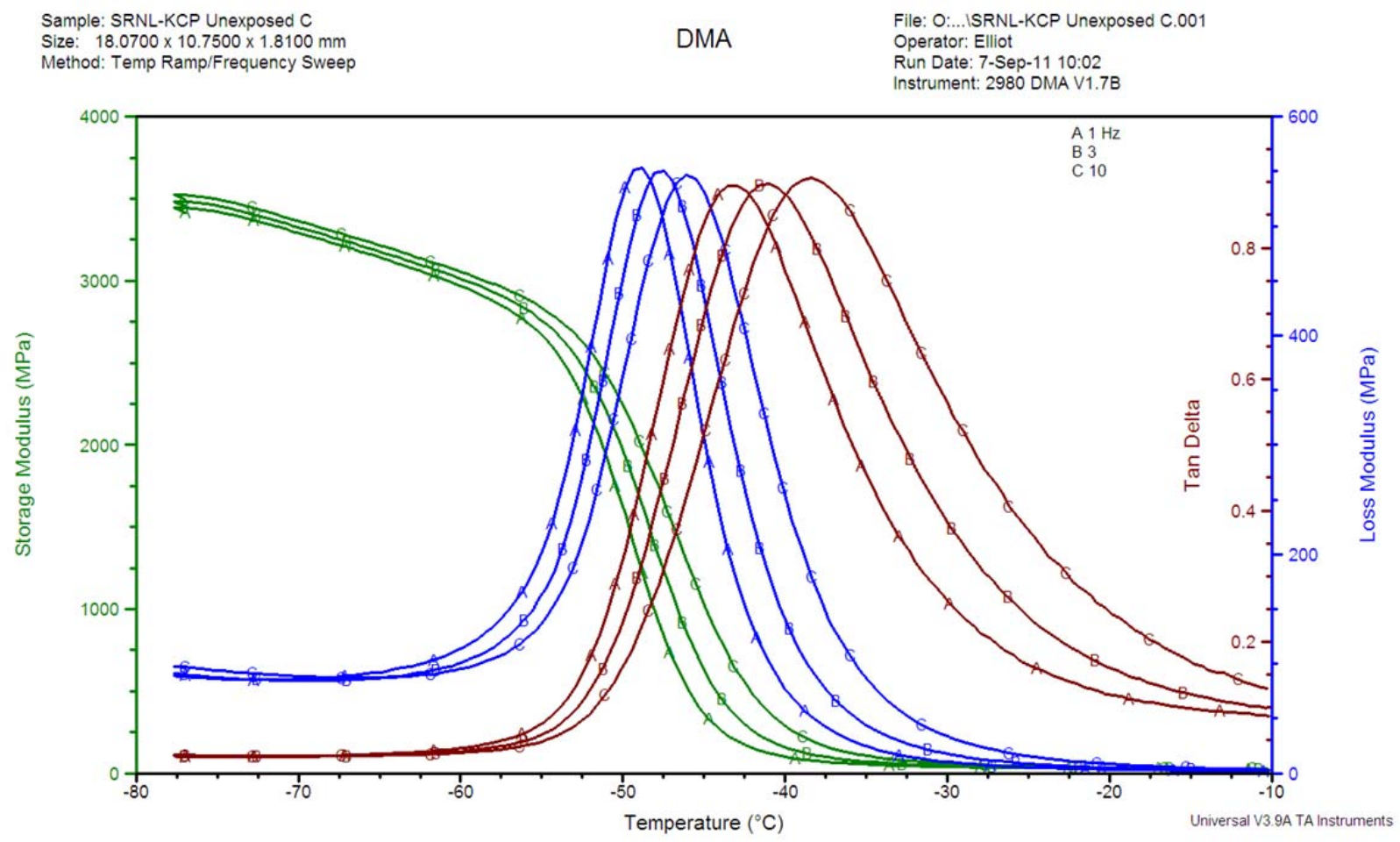

Figure 5. Storage Modulus, Loss Modulus, Tan Delta of unexposed SRNL-KCP sample C. Test run from $-80{ }^{\circ} \mathrm{C}$ to $-10{ }^{\circ} \mathrm{C}$ at $1{ }^{\circ} \mathrm{C} /$ minute. Excitation frequencies indicated by A- 1 $\mathrm{Hz}, \mathrm{B}-3 \mathrm{~Hz}, \mathrm{C}-10 \mathrm{~Hz}$. 


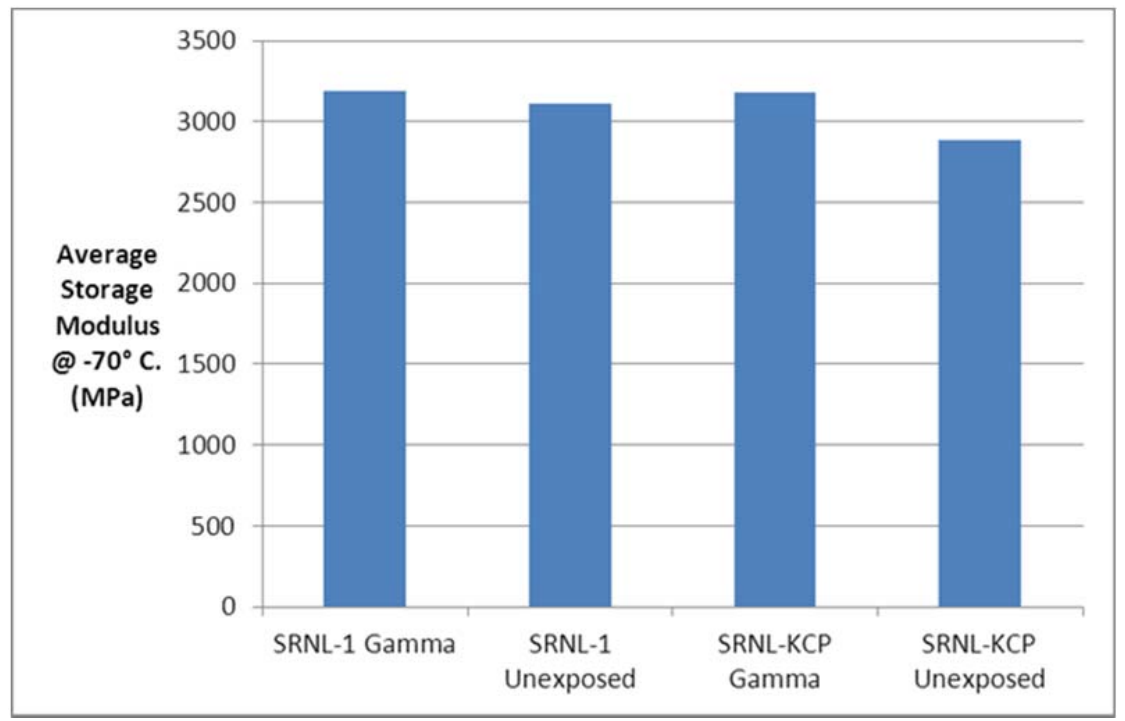

a.

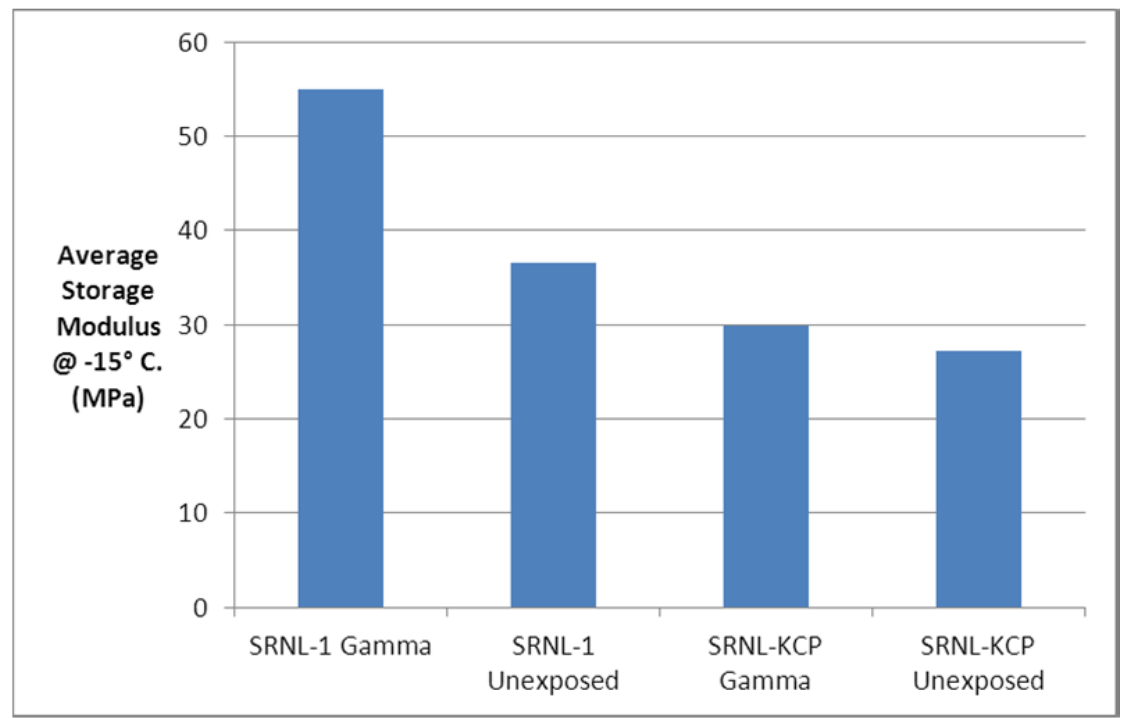

b.

Figure 6. Average storage modulus for the formulations and gamma exposed/unexposed samples; a. at $-70^{\circ} \mathrm{C}$., b. at $-15^{\circ} \mathrm{C}$. 